\title{
Methods of Effective Governance of Territorial Transformations in Russian Federation
}

\author{
S. N. Fedorova \\ Candidate of Science in Economics, Southwest state university, Kursk, Russia \\ Email: svetl-fedorova@mail.ru
}

Doi:10.5901/mjss.2015.v6n5s2p350

\begin{abstract}
Considerable territorial differentiation existing in Russia today contributes to both federal and regional economic slowdown. Alongside with that, gaining control over the process of territorial differentiation at the micro-level in order to reduce disparity among rural municipalities and to ensure their sustainable development, is considerably hindered, taking into account the gap between the tasks local self-governing bodies have to accomplish and the financial resources at their disposal. Territorial transformation of municipal entities (regional rural settlements) may become one of the possible solutions to the problem. That would make it possible to optimize local administrative machineries, to reduce imbalance and disparity in economic development of rural municipalities and to channel the funds released towards the vital problems of local significance. However, the problem of preliminary comparison of socio-economic development rates of municipal entities within a region, which is required for further successful implementation of strategies of rural territorial transformations, still remains unsolved, since currently no generally acknowledged and scientifically based specific methods for that purpose are available. As the result of the theoretical and practical research work carried out by the author, the article presents the territorial transformation procedure algorithm and proposes the model to evaluate synergistic effect of the activities intended to foster optimization of territorial structure of rural areas.
\end{abstract}

Keywords: territorial differentiation, regional rural settlements, socio-economic development rates, territorial transformations.

\section{Introduction}

At present most European countries including Russia experience the process of authority shifting to the primary territorial and administrative (municipal) level as far as socio-economic aspects of their development are concerned. In this respect the special reference is made to enhancement of local self-development sustainability and self-reliance in rural areas. However, taking into consideration the present-day environment for economy management in Russia, local self-governing does not mean local self-sustained budget. Financial resources local self-governing bodies have at their disposal are miniscule compared to the tasks they have to perform at their level; whereas, expenditures on maintenance of local administration machinery for many municipalities reach $40-90 \%$ of the total local budget amounts as reported by the Ministry of Finance. Thus, expenditures on maintenance of local administration machinery per inhabitant of a municipality 3 to 16 times exceed people's average earnings.

In comparison, let us consider the situation typical for centralized administrative system as part of the Soviet economic system based on centralized planning. Rural population life totally depended on particular aspects of performance of collective and state farms or other rural enterprises imposed to resolve socio-economical matters at local scale. It was also regulated by Rural Council (Rural Soviet) activity. State-region, region-town and region-district, districtsettlement relationship represented a bottom-up pyramid where major funds to secure proper authority performance were concentrated at the state power level (Fig. 1-a).

In Russian Federation the recent decades of reforming have resulted in grave imbalance of tasks imposed on local self-governing bodies and financial resources available. Consequently, it has led to actual failure of implementation of socio-economic development program, contraction of the volume of budget-funded services to the public and entailed economic, demographic, social and cultural crisis in non-urban areas. 

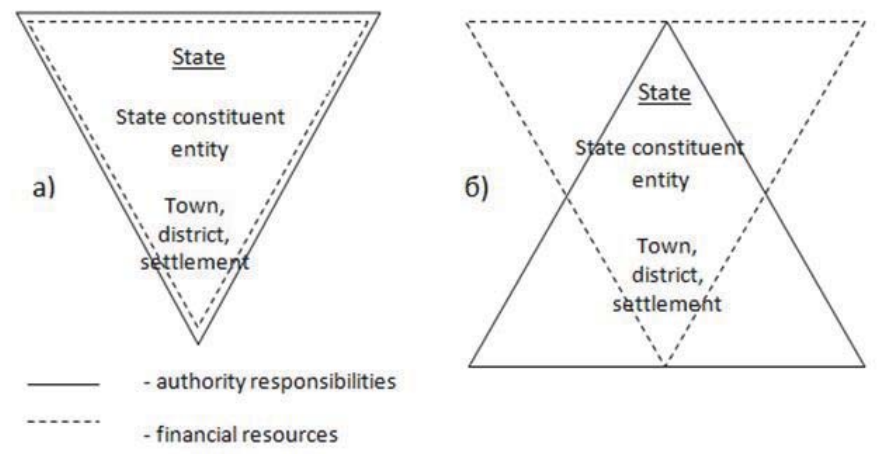

Figure 1. Pattern of the distribution of financial resources to secure authority responsibilities in centralized (Soviet) (a) and de-centralized (present-day Russian) economic contexts (b).

The distribution of financial resources to secure authority responsibilities at different power levels in present-day decentralized economic context is visually represented in Fig. 1 (b).

The existing operation pattern for local authorities does not respond the provisions of European Charter of Local Self-Government ratified by Russia in 1996, Article 9 of which prescribes: "Local authorities shall be entitled, within national economic policy, to adequate financial resources of their own, of which they may dispose freely within the framework of their powers", "Local authorities' financial resources shall be commensurate with the responsibilities provided for by the constitution and the law".

The thrust towards development of non-urban territories is among the mainstream agricultural policies of the European Union (EU) Member States. Alongside with the EU general fundamental approaches to solving the rural area and agriculture development problems, each of the EU Members states its national rural policy priorities through elaboration of programs and strategies related to the issue.

\section{Research Methodology}

In the context of worldwide economic globalization processes, particular regions and municipal entities, as well as countries, take a position of full-fledged parties to economic relationship not only at interregional, but also at international scale. They go into tough competition for market outlets and funds. The ability of state, regional and local bodies of power to clearly set strategic priorities, to improve business climate, to effectively distribute and improve the quality and value of regional (municipal) resources and infrastructure create beneficial background for enhancement of sustainable competitive advantages of a region and municipalities within.

Fusion of autonomization-integration processes has become a specific feature of regional (municipal) economic performance in western countries. The phenomenon was rendered in John Naisbitt's "Global Paradox", where the following correlation is shown: "the bigger the world economy, the more powerful its smallest players". (Naisbitt J., 1994)

Taking the existing world trends into consideration, elaborating and enacting of the essential legislative instruments for successful territorial development shall be regarded as a top-priority objective within the framework of the state policy.

According to the Ministry of Finance of Russian Federation expert assessment data, "...as a result of the budget system development... local budgets have lost $50 \%$ of corporate property tax, $2 \%$ of corporate profit tax and excise tax as their revenue sources; the share of individual income tax assigned to local self-government decreased from $50 \%$ to $40 \%$. Municipal units of different types lack 40 to $50 \%$ of funds required; more than $70 \%$ of municipal units are subsidized".

Due to a number of environmental, areal and socio-economic factors, a specific feature of Russian economy is considerable territorial differentiation among rural settlements regarding the rate of their socio-economic development and self-sufficiency in their own revenue sources.

The steps Russia's federal and regional policy makes towards equalization of municipal development levels do not produce the effect desired; the gap between donor and recipient municipalities is becoming even wider. This state of affairs entirely confirms Paul Krugman's model of industrial development based on cumulative causation theory, the main idea of which is that firms (manufacturers) gravitate towards high density economic spaces (i.e., "core" areas), and 
economic density in turn tends to increase where the concentration of firms is higher, that is, in well-developed polarized municipal entities. (Krugman P., 2012)

In this respect we cannot but refer to Jacques Boudeville's research work completed in the middle of the last century, which is also of great interest. It defines the following types of abstract economic spaces: homogenous, polarized and planned ones. Underdeveloped territories are featured with homogenous economic space, but in the course of their further development the economic space inevitably tends to polarize. In the scientist's opinion not every territorial centre makes a growth pole, but only where propulsive industries are developed. Thus, in accordance to the present theory, the initial step towards economic development of municipalities is their thorough exploration for detecting industries which would become drivers to development of all the municipalities within a region.

The present-day scientific community has not built a consensus upon the necessity to gain control over the differences among the development levels of different territories. There are two polar attitudes to the issue:

1. A country (or a region) is unable to develop in the proper way if socio-economic differences among the administrative (municipal) entities are too large;

2. The process of development of territories runs in such a way that it inevitably causes and reinforces territorial disparity.

In our opinion, these two counter attitudes can not sufficiently address the issue of disparities in the development of municipalities; for that purpose it is necessary to maintain the balance between centralization and de-centralization processes.

It seems important to highlight the following distinctive features of Russian economic space configuration:

- large disparity as a consequence of different economic process velocity in different regions;

- $\quad$ high sparseness as a consequence of poor development of the territory of Russia and low population density;

- $\quad$ pike-shaped profile as a consequence of dense concentration of economic space activity around large cities only.

The science of economic geography proposes a great number of different approaches to classifying regions, districts, zoning types, although the lower economic unit, i.e. a municipality (that is rural settlement) is not considered. On the basis of district classification proposed by George Friedman we suggest the following classification of rural settlements:

- core rural settlements, those are central well-developed rural settlements;

- growing rural settlements. Those are peripheral rural settlements, although their location in close vicinity to core settlements facilitates their further growth and development;

- $\quad$ pioneer rural settlements (new development territories), located in remote and previously hard-to-access areas which are currently in the process of settlement and development;

- depressed rural settlements with stagnating agriculture and industry, which is aggravated by a number of socio-economic problems (unemployment, decline in living standards etc.);

- rural settlements with poor living conditions, featured with unfavourable environment (as the combination of natural, climatic, geographical and socio-economic factors);

- stagnating rural settlements. The pace of their development is equal to zero or even has a negative value.

Differentiating among rural municipalities (subdivision of an area into micro-districts) may be considered as one of the levels of screening within the frame of the classification procedure in an effort to detect similar municipalities on the ground of their common characteristics and connections. Singling out rural municipalities may be accomplished in two ways: by means of merging (integration) or de-merging (disintegration). Merging on the basis of the commonality of their characteristics results in singling out a particular homogeneous rural municipality, while carried out on the basis of the commonality of connections it gives a particular nodal point settlement (municipality).

Functioning of rural municipalities is conditioned by a number of the distinctive nation-specific features of rural life in Russia, among them: spatial separation of life and operating activities; focus on agriculture as the main priority economic sector; economy pattern based on small family-type enterprises; mutual aid networking; specific mentality of rural population etc.

For instance, spatial separation of life and operating activities, which demands extensive production spaces and facilities, has led to large depopulation in a great number of settlements.

Agriculture remains the main branch of rural economic activity. For a long period of time the concepts of "development of rural territories" and "agriculture development" were considered as identical to each other, while the role and mission of rural areas reduced to securing food supply and providing agricultural raw materials to meet the country demand. (Barlybaev A., Aidarbakov F., Rakhmatullin B., 2013)

In an effort to revive rural territories, to enhance the independency of local self-government bodies, creation of a 
strong regional-level platform for attraction of sufficient investment volumes to ensure development of all kinds of enterprises and economy patterns shall become one of the first priority tasks.

The patterns of industrial and labour activities in rural areas (especially in private enterprises) are shaped by a number of factors: prevalence of family-type enterprises, large families with many children and active involvement of children into work, which is also the way to solve the problem of raising the oncoming generation in the spirit of respect for socially useful activity. Taking part in the family work from an early age children gain substantive experience and knowledge essential for their further individual life, form thrifty attitude to the property, domestic animals; they grow more independent and persevering, as evidenced by the background of a number of the country's intellectual, political and public elite representatives. To support the traditional conception of continuity of generations Russian Prime Minister Dmitry Medvedev declared a federal targeted project of founding the so-called "ancestry demesne lands" in rural areas.

In order to survive in the period of the post-Soviet crisis rural population initiated informal mutual aid networking involving close relatives, friends, neighbors or people from the same village. The aim of such kind of networking is "informal co-operation and consolidation of forces, resources and goods of all the families within a cluster in an effort to maintain the obtained level of well-being and life quality for every cluster family in particular or to achieve the possible maximum average socio-economic status". (Barlybaev A., Aidarbakov F., Rakhmatullin B., 2013)

The idea of mutual aid networking is also a kind of reflection of the mentality of Russian rural population which has always been oriented towards collective land use, motivated not by a personal self-interest or even not by economic expediency, but guided by the traditions established in the local community.

Within a rural community in Russia the concepts of my and our have always been rather vague and rural people make little distinction between them. On one hand, it fosters stronger motivation for careful attitude to the common living environment; on the other hand, however, it inspires prejudice against private owners.

A number of scientists studying regional problems share the view that it is hardly possible to explain the character of the present-day trends of municipal territorial development and the nature of their differentiation just basing upon particular national special features.

The specialness of a rural municipality, as Alexander Domashenko sees it, is that "it has the capability to survive with very slim chance for success and in most unfavorable conditions... That is determined not only by influence of a particular object or an event, but of the general aggregate of the events in the world around. The unique nature of a rural municipality demands the utmost attention to its special features, regular diagnosing and monitoring of the emerging changes". (Domashenko A., 2006)

In this respect, the main target of the present studies is to define the threshold level of socio-economic development for a municipality to secure comfortable rural life conditions including the principle of social fairness.

Tom Geiger, an American specialist in development of local communities [8], noted that comfort conditions as well as a small community development potential depend on at least 5 key development factors and their availability: funds, knowledge, transportation lines, external environment and telecommunications. The list suggested is rather disputable; however one cannot but admit that the factors mentioned directly influence the level of socio-economic development of a municipality.

Territorial management and administration theory and practice distinguish two general lines to equalize rural settlements' development rates:

- administrative and legal control of center-region and region-local power interaction process;

- inter-budget relations.

Both Russian and foreign theory and practice in this field suggest a number of methods to enhance territories' own revenue base. They are commonly subdivided into "conventional" and "nonconventional". Conventional methods are:

1) expansion of the range of local taxes, fees and charges;

2) implementation of measures for better tax collection and boosting non-tax revenues (disclosure of "hidden" objects of taxation, improvement of recording and inventory-making efficiency, carrying out activities on recovery of arrears etc.);

3) revision of tax elements (repeal of reliefs, raising of tax rates);

4) setting higher rates of fees for municipal property rent;

5) raising of ratio of regional and federal fiscal transfers to local budgets;

6) setting higher fees for chargeable services provided to the public by local self-government bodies and budget public-sector organizations within their jurisdiction.

Most of the actions mentioned (growth of fees for chargeable services provided to the public by a local selfgovernment and budget public-sector organizations within their jurisdiction, repeal of reliefs, raising of tax rates etc.) entail anti-social effects; thus, they cannot contribute to any sensible improvement of socio-economic climate in rural 
areas.

Nonconventional methods employed to enhance rural settlements' own revenue suppose drastic measures taken within the state tax policy aiming at optimization of municipal territory structure (territorial transformation).

We judge it expedient to point out the following basic methods of conducting territorial transformation of municipalities within a region: merging (integration), de-merging, status alteration and abolition. The given classification is not inconsistent with Art.13 of the Federal Law №131-FL "On General Principles of Local Self-Government Organization in Russian Federation", which treats the term of "territorial transformation" as synonymic to "restructuring". Any method of municipal transformation results in establishing new municipal entities.

Here are brief definitions to the methods mentioned.

Merging (integration) is territorial merging of two or more municipalities which does not affect the other regional municipalities' boundaries. Municipal entities subject to be integrated loose their status and are excluded from the Register of the Administrative-Territorial Entities and Localities of the Federal Constituent Entity.

De-merging is subdivision of a single municipality into two or more; afterwards, it looses its status and is excluded from the Register of the Administrative-Territorial Entities and Localities of the Federal Constituent Entity.

Status alteration is restructuring of a municipal territory by the Law of the Federal Constituent Entity; as consequence, the municipality under status alteration is subject to be withdrawn from (or included into) the region structure.

Abolition of a rural municipality is the loss of its status as a municipal entity and its registration as an intersettlement territory with the consent of its residents. Abolition of rural settlements is permissible in areas with low population density and in hard-to-access areas, if the settlement population is less than 100 people.

Severe demographic crisis in rural areas occurs throughout the country; although, in accordance with the Law, "decrease in a rural settlement population less than $50 \%$ of the minimum standard... does not constitute sufficient grounds for... changing the settlement boundaries".

Taking regional specific contexts (from the perspective of institutional factors, resource, production and other potentialities for a particular municipality) into consideration is an important principle to adhere to in the course of transformation of a territory.

Governance of the process of territorial transformations on the level of municipal entities is a purposive activity of the interested participants in the process in an effort to create and secure regulatory, economic and social conditions which would foster economic recovery, fledging, development and realization of the municipalities' potential competitive opportunities.

The particular aspect of governance of territorial transformations is that it involves recording and analyzing of the following characteristics: the process duration, the coverage breadth, the process phasing, the factors of direct and indirect influence.

Governance of the process of territorial transformations enables upward transition of the municipal entities under transformation to a higher level of their development due to realization of apparent and hidden potential of the territories.

Obtaining benefits by means of improving the system properties is known as synergistic effect; in this case we speak about the effect of a territory transformation towards integration. Despite synergistic effect integration of rural settlements is considered to gain advantageous economy by scale.

Conducting territorial transformations of municipal units demands following the principles given below:

- transformation of territories shall be carried out taking the commonality of a number of their characteristics (resources, geographical landscape, etc.) and connections as a premise;

- $\quad$ none of the municipal units shall be involved in the process of transformation twice;

- it is obligatory to adhere to the principles of merging (integration) and de-merging (disintegration) at every step of the transformation process;

- transformation criteria shall be geographically conditioned and reasoned.

To-day a great number of strategies for differentiating among territories have been elaborated. But not each of them is equally relevant for detection the "poles of growth" and, on the contrary, the "lagging-behind" among the rural settlements of interest.

\section{The Main Part of Research}

The overall objective of the socio-economic analysis of the municipal entities under transformation is:

- to consider the process of transformation for the rural settlements being joined in order to identify of its actual necessity, risks it carries, possibilities it gives, its effectiveness; 
- to creating analytical information base (on the stage of transformation strategy setting);

- to anticipate and identify factors that may entail deviation from the strategy baseline (on the stage of merging, or integration) in a timely manner;

- to evaluate financial and operational synergies gained as a result of transformation of rural settlements, or identify causes for its absence;

- to identify causes for de-merging (disintegration) of a municipal entity transformed, its consequences and effects.

The definition of the overall objectives of the analysis of processes intended to optimize territorial structure of rural settlements requires further detailed specification focusing on the stages of the life-cycle of a transformation of municipalities. Figure 2 presents the curve of the life-cycle of a transformation of municipalities, which was developed within the research framework.

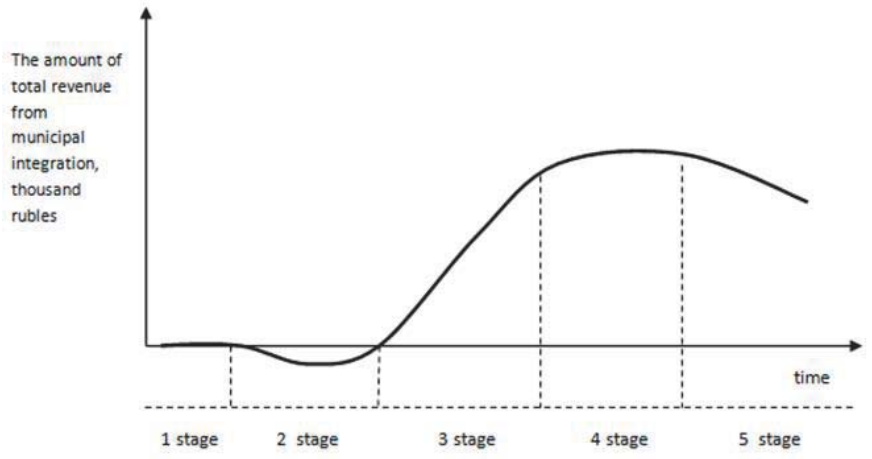

Figure 2. The curve of the life-cycle of a transformation of municipalities

According to the curve, the life-cycle of a transformation of municipalities covers the following stages:

I - the pre-transformational stage, which includes: benchmark data identification (key figures to evaluate the level socio-economic development of the municipalities in the region); analysis of socio-economic potential of the territories, detection of the "lagging-behind" and the "growth poles" among them; building a qualified managing team to implement the transformation activities; setting up the strategy for the territorial transformation; identification of criteria the municipalities under transformation shall meet; consideration of possible transformation variants, negotiating process with the local self-governing bodies, and the population of the municipalities selected; conducting the referendum; process;

II - the stage of transformation, which includes the transformation expending and legal arrangements for the

III, IV - post-transformation stages (initial perception of the territory changes and the integrated municipality actual performance), where:

III - the stage of a positive synergistic effect achieved after integration (merging) of municipalities;

IV - the stage of sustainable development and zero synergistic effect;

$\mathrm{V}$ - the stage of re-transformation (territorial de-merging).

The last stage has been provided to face the generally possible scenario, where, although the territories transformed may enjoy sustained socio-economic climate and competitiveness, proper synergistic effect may not be obtained.

In our opinion, the period of starting and ensuring effective operation at the local level, of initial perception of the territory changes may take several months to several years.

The main target of local self-governing bodies in the newly established municipalities (rural settlements) is to improve local population life. That may be achieved by means of attracting investments, participating in regional, federal and international grants, targeted programs for agricultural areas development.

Since synergistic effect achieved as a result of municipality integration (merging) requires mathematical evaluation, the mathematical model for synergy calculation was developed.

Positive synergistic effect $(\Delta R)$ as a result of municipality integration appears only under following conditions: 


$$
\left\{\begin{array}{l}
A 0+B 0+D 0=R 0 \\
A 1+B 1+D 1=R 1
\end{array} \Rightarrow \Delta R=R 1-R 0>0,\right.
$$

where: $\mathrm{AO}, \mathrm{BO}, \mathrm{D} 0$ are revenues to municipal budgets before the integration, $\mathrm{RO}$ is the total of the revenues;

A1, B1, D1 are revenues to the budgets of the municipalities which have become the components of the newly established integrated municipality, R1 is the total revenue of the newly established integrated municipality.

Although the integrated municipal entity may enjoy sustained socio-economic climate and competitiveness, proper synergistic effect may not be obtained, and vice versa.

In order to calculate economic effect arising from territorial transformation, the system of linear equations was analyzed (2):

$$
\left\{\begin{array}{l}
F_{A B}=\sum_{j=1}^{n !}\left(P_{n !} \cdot S_{n l}+P\right)=n_{1}\left(P_{1} S_{l}+P\right) \\
F_{F E}=\sum_{i=1}^{n 2}\left(P_{n 2} \cdot\left(S_{n 2}+S_{\Delta n}\right)+P\right)=\left(P_{1} S_{l}+P\right)\left(n_{1}-\Delta n\right)+P_{1} S_{\Delta n} \\
\ni=F_{A E}-F_{P z} \rightarrow \max
\end{array}\right.
$$

where $F_{A E}$ and $F_{P E}$ are actual and planned financial expenditures on maintenance of local administration machinery in the municipalities observed; $n_{1}$ and $n_{2}$ represent the number of municipal entities before and after transformation; $P_{n 1}, P_{n 2}, P_{1}$ are expenditures on maintenance of local administration machinery per staff member; $S_{n 1}$, $S_{n 2}, S_{1}$ represent the average staff number; $P$ is the average salary of chief executives of rural settlements; $S_{\Delta n}$ is a possible number of municipal administration staff members remaining after municipal administration machinery downsizing; $\mathrm{E}$ is economic effect of the transformation implicated. Here, $n_{1}-n_{2}=\Delta n$, provided that $0 \leq \Delta n<n_{1}$, $S_{\Delta n} \leq \Delta n$

The objective function we have constructed (3) requires the following condition to be observed in order to achieve positive economic effect:

$$
f\left(\Delta n, S_{\Delta n}\right)=\frac{F_{A B}}{F_{P E}}=\frac{\left(P_{1} S_{1}+P\right) n_{1}}{\left(P_{1} S_{1}+P\right)\left(n_{1}-\Delta n\right)+P_{1} S_{\Delta n}}>1 ; \quad \Delta n>\frac{S_{\Delta n}}{P_{1} S_{i}+1}
$$

Taking into account that $K_{\Delta n} \leq \Delta n$, the inequality (3) is correct for all the values of $S_{1}$ and $S_{\Delta n}$.

$$
\mathrm{D}(f): \Delta n \in\left(S_{\Delta \mathrm{n} .} /\left(\left(P_{1} S_{1} / P+1\right)\right) ; \alpha n_{1}\right), 0 \leq \alpha<1
$$

where $\alpha$ is a selectable coefficient set with consideration of the legislative restrictions and the data of the socioeconomic analysis carried out.

Depending on the number of municipalities consolidated $(\Delta n)$, and taking into account that

$S_{\Delta \mathrm{n} .}=\beta \Delta n, 0 \leq \beta \leq 1$,

the economic effect is calculated in the following way:

$$
\mathrm{E}=\left(P_{1}\left(S_{1}-\beta\right)+P\right)^{\Delta n} \text {, }
$$

where $\beta$ is a selectable coefficient which rates the number of administrative staff members left in the consolidated municipality.

The funds released as a result of the economies of scale may become base source of financing for municipal investment programs, which is one of the components of internal investment potential of municipalities within the region.

\section{Conclusions}

The proposed methods of governance of a municipal transformation within a region and the analysis of the stages the process covers by no means claim to be indisputable. However, they shed light on the complexity and arduousness of the subject matter, its multi-dimensional nature. They give evidence to the undeniable importance of elaborating solutions to the issue, i.e. the strategies and methods for territorial structure optimization at the lower administrative level (micro-level) of municipal entities (rural settlements). As a result of their successful implementation the following potential advantages may be achieved:

1) administrative advantages, such as: improvement of governance quality; eliminating of overlapping the 
elements of an administrative organization structure; increased strategic planning capability; possibility to concentrate the forces and resources on top-priority goals; improvement of the administrative staff qualification;

2) enhancement of flexibility on the financial market: increased liquidity for the integrated municipality compared to the municipalities before the integration (merging); optimization of the resource base structure; facilitating of access to credit resources; reduction of the attracted resource cost; capability for extensive funding applied to the local social development; consolidation of financial flows and consequently, capability for effective investment policy implementation;

3) competitive advantages, such as: the full range of services provided to the public by local self-government bodies; improvement of the quality of the services provided; expansion of the marketing area; the possibility to channel the finance towards socially significant problems of the settlement; non-manufacturing cost reduction; arising of technological and marketing possibilities for establishment of new or revitalization of old industries and enterprises; ability to adjust to the context changes.

Elaboration of a system-based approach to investigation into the issues of transformation of territorial structure of municipal entities in Russia just takes initial steps. The importance of the problem we face is determined by the urgent need for drastic reconsideration of the role and place of primary-level municipal entities in the context of the fundamental transformations which concern all the country life aspects and are intended to ensure optimum conditions for the functioning of society.

\section{References}

Russian Federation. Federal targeted program "Reduction of Disparities in Socio-Economic Development of the Regions of Russian Federation (2002 to 2010 and up until 2015)" http://www.akdi.ru/ECONOM/program/region.htm

Russian Federation. Ratified Charter of Local Self-Government. http: // www.consultant.ru

Global Paradox. The Bigger the World Economy, the More Powerful Its Smallest Players. William Morrow \& Company, Inc., 1994

Methods of the assessment of socio-economic development of the regions. Research and Production Association "Krista" HПO «Криста»/ www.krista.ru/

Krugman P. Speed Trap. The fuzzy logic of the «New Economy». http://web.mit.edu/krugman/www/speed.html.

A.A. Barlybaev, F.F. Aidarbakov, B.V. Rakhmatullin. The development of rural territories during the post-Soviet period: the institutional aspect. / http://institutiones.com

A.A. Domashenko. Methods of the comprehensive assessment of development of a municipal unit. // Legal and socio-economic problems of the transition of a municipal entity to local self-governance. Proceedings; edited volume/ Volgograd State University, the Urjupinsk Branch. - Volgograd: Volgograd State University Press, 2006.

T. Geiger. The development of local communities. From the lectures delivered in Krasnodar. Manuscript. 1998.

Russian Federation. Federal Law № 131-FZ dated 6 October 2003 "On General Principles of Local Self-Government in the Russian Federation". - http: // www.consultant.ru 